\title{
Assessment of Gut Bacteria Profile and Antibiotic Resistance Pattern Among Psychotropic Drug Users: Comparative Cross-Sectional Study
}

\author{
Mulatu Gashaw' \\ Zufan Hailu Marame ${ }^{2}$ \\ Mubarek Abera ${ }^{3}$ \\ Solomon Ali (D) ${ }^{4}$
}

'School of Medical Laboratory Science, Jimma University, Jimma, Ethiopia; ${ }^{2}$ Ambo University Referral Hospital Microbiology Laboratory, Ambo University Referral Hospital, Ambo, Ethiopia; ${ }^{3}$ Department of Psychiatry, Jimma University, Jimma, Ethiopia; ${ }^{4}$ Department of Microbiology, Immunology and Parasitology, Saint Paul Hospital Millennium Medical College, Addis Ababa, Ethiopia
Correspondence: Mulatu Gashaw School of Medical Laboratory Science, Jimma University, P.O. Box: 378, Jimma, Ethiopia

Email mulatugashaw@gmail.com
Introduction: In the twenty-first century, antibiotic resistance is becoming one of the major global public health threats. Several complex factors are associated with the emergence and spread of antibiotic resistance. Emerging evidences are indicating that drugs used for chronic illness conditions might have a contribution for antibiotic resistance either through drugdrug interactions or metabolism of the drugs by gut microbiota.

Objective: The aim of this study was to compare the bacteria profile and resistance patterns of gut bacteria isolated from participants using psychotropic drugs and apparently healthy controls. Methods: Socio-demographic data were collected from patients using psychotropic medications and apparently healthy persons. Clinical data were collected from patient records. Stool samples were collected from 107 patients using psychotropic medications and 107 apparently healthy controls. Gut bacterial flora were isolated and identified using oxidase, indole, and BD BBL crystal Enteric/Non-fermenter identification system. Antibiotic susceptibility test was done using the disk diffusion method, and Mast disks were used to identify extendedspectrum betalactamase (ESBL) and/or AmpC-producing isolates.

Results: A total of 245 bacterial isolates were isolated and identified. From these, 124 $(50.6 \%)$ bacteria were isolated from patients using Psychotropic medications. There was no bacteria profile difference between the two groups. Escherichia coli was the prevalent [100 $(80.6 \%)$ and $102(84.3 \%)]$ bacteria isolated from patients using psychotropic medications and apparently healthy controls, respectively. Escherichia coli isolated from patients using psychotropic medications showed significantly higher resistance against amoxicillinclavulanic acid, cephalosporin (2nd, 3rd, 4th generations), meropenem, ciprofloxacin and tetracycline. The odds of isolating ESBL-producing Enterobacteriaceae $[(\mathrm{OR}=2.3,95 \%$ C.I: (1.4-4.0)] and MDR [OR=5.4, 95\% C.I: (1.5-29.8)] were higher on patients using psychotropic medications.

Conclusion: The observed antibiotic resistance pattern of bacteria isolated from guts of patients using psychotropic medications was very high. The magnitude of antibiotic resistance is more pronounced among $E$. coli isolates.

Keywords: antibiotic drug resistance, psychotropic drugs, gut bacteria

\section{Introduction}

Emergence and spread of antibiotic resistance are a long-standing universal public health problem in the past few decades. ${ }^{1,2}$ Antibiotic resistance in gram-negative bacteria, particularly in coliform opportunistic Enterobacteriaceae are a priority global public health concern. ${ }^{3,4}$ These group of bacteria reside in the human gut 
and have already acquired resistance against most beta lactam antibiotics including 3rd generation cephalosporins and carbapenem antibiotics and they can be the source of drug resistance for other pathogenic microbes. ${ }^{5}$

The human gut contains a tightly populated microbial ecosystem that provides ample opportunities for horizontal transfer of genetic materials like antibiotic resistant genes ${ }^{6}$ or colonization with MDR bacteria. ${ }^{7}$ Various internal and external factors such as age, mode of delivery, environment, diet, genetics and immune responses, prebiotics, probiotics, antibiotics, and non-antibiotic medications can affect the composition and potentially disrupt the ecological balance of the gut microbiota. ${ }^{8,9}$

Though, non-antibiotic drugs are developed to treat noninfectious disease, they might have an effect against bacteria. A number of non-antibiotic drugs such as anti-inflammatory drugs, calcium channel blockers, and antidepressants have been reported to exhibit some bactericidal or bacteriostatic activity. ${ }^{10}$ For example, the antidepressant Fluoxetine induces multiple antibiotics resistance in Escherichia coli via reactive oxygen species (ROS)-mediated mutagenesis. ${ }^{11}$ Thus fluoxetine may play a crucial role in the spread of drug resistance in a community because commensal bacteria serve as the reservoir of antibiotic resistance genes and resistance to a more virulent organism. ${ }^{12}$ Other non-antibiotic medications like antipsychotics inhibit the growth of at least one strain of bacteria commonly found in the gut of healthy humans. ${ }^{9}$

The current knowledge on the association between non-antibiotic medication usage with gut bacteria profile and resistance pattern is not conclusive given that most of the evidences are reported from high-income settings. Therefore, this study aimed to compare the gut bacteria profile and antibiotic resistance pattern of opportunistic coliforms isolated from psychotropic drug users and nonusers at low resource settings, Jimma Medical Center, Ethiopia.

\section{Methods}

\section{Design and Settings}

A comparative cross-sectional study was carried out from March to June 2019 at Jimma Medical Center (JMC) psychiatric clinic. In the setting, a total of 750 psychiatric patients have regular follow-up visit to the clinic every month. Currently, the clinic has more than 60 inpatient beds for general adult and child psychiatric patients and substance detoxification treatment. ${ }^{13}$

\section{Subjects}

Group A: are psychiatry patients who were admitted or had follow up at JMC psychiatry clinic and taking single or combined psychotropic drugs from antipsychotics, antidepressants, or mood stabilizers medications during the study period. Group B: are some volunteer postgraduate students or patient companions from medical outpatient department (OPD) in JMC who had never been on psychotropic drugs. Participants who did not take antibiotic drugs with in the last six months of the data collection date in both groups were enrolled in the study and the age and sex of the participants in both groups were matched.

\section{Sample Size}

The sample size was calculated by using EPI-INFO version 7 using the following assumptions. Since there were no similar studies conducted on this specific research topic so far, by considering psychotropic drug use as an exposure variable, it was decided to take $50 \%$ of exposure in both groups. In addition, $95 \% \mathrm{CI}, 80 \%$ power and 1:1 ratio was taken. Finally, the sample size includes a total of 107 psychiatry patients and 107 apparently healthy controls. Consecutive sampling technique was employed to include study participants who met the inclusion criteria.

\section{Data Collection Background Data}

Pre-designed and semi-structured questionnaire was used to collect socio-demographic characteristics. The clinical information for group A participants was collected from patient records.

\section{Laboratory Data}

Five-gram fecal samples were collected in a sterile widemouth screw-capped container and then inoculated on MacConkey agar (Oxoid, Ltd., UK). After overnight incubation at $35-37^{\circ} \mathrm{C}$, suspected colonies on MacConkey agar plates were further identified and confirmed by the pattern of biochemical test using oxidase, indole, and BD BBL crystal Enteric/Non-fermenter identification system (BD, USA). ${ }^{14}$

\section{Antimicrobial Susceptibility Testing}

Antimicrobial susceptibility testing of the isolates was performed using the Kirby-Bauer disk diffusion technique

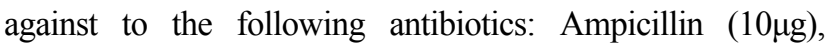
Tetracycline $(30 \mu \mathrm{g})$, Chloramphenicol $(30 \mu \mathrm{g})$, Ciprofloxacin $(5 \mu \mathrm{g})$, Trimethprim-Sulphamethazole $(25 \mu \mathrm{g})$, Gentamycin $(10 \mu \mathrm{g})$, Ceftriaxone $(30 \mu \mathrm{g})$, Cefotaxime $(30 \mu \mathrm{g})$, Ceftazidime 


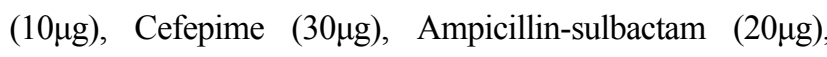

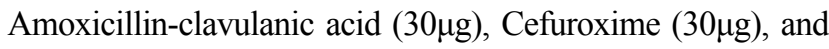
Meropenem $(10 \mu \mathrm{g})$. Then, the plate was incubated at $35-37^{\circ} \mathrm{C}$ for 18-24 hours, and the results were interpreted according to CLSI. ${ }^{15}$

\section{ESBL and/or AmpC Detection}

The presence of an ESBL and/or AmpC was determined

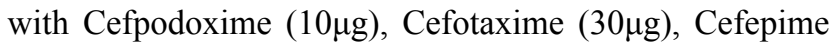
$(30 \mu \mathrm{g})$ and Ceftazidime $(30 \mu \mathrm{g})$ containing antibiotic discs (Mast Group ltd, UK) by disc diffusion confirmation test. Finally, zones of inhibition were read and recorded on excel sheet and transported to Mast group ESBL/AmpC and CARBA plus calculator spreadsheet and reported as negative or positive for ESBL or/and AmpC.

\section{Quality Control}

To standardize the inoculums density of bacterial suspension for the susceptibility test, a 0.5 McFarland standard was used. Susceptible reference strains of American Type Culture Collection (ATCC) E. coli 25922 was used to assure antimicrobial susceptibility testing using exactly the same procedure as for the test organisms and the results were only accepted when the inhibition zone of control strain was within the ranges as described by CLSI $^{15}$ and K. pneumoniae ATCC 700603 were also used for ESBL detection as a positive control.

\section{Statistical Analysis}

The data were entered into Epi data manager version 4.4.1 and exported to statistical package for social science (SPSS) version 21 for statistical analyses. Descriptive statistics for percentages and mean were calculated. Odds ratio and Chi-square test were employed to compare the bacteria profile and antibiotic resistance of gut bacteria between group A and Group B participants. P-value $\leq$ 0.05 was considered as statistically significant.

\section{Ethical Consideration}

This research was approved by Jimma University Health Institute, institutional review board (IRB). Permission was obtained from the JMC management unit. Written informed consent was obtained from the study participants and/or their guardians. The collected data was kept confidential. The specimens collected from the participants were analyzed only for the intended purposes. The pros and cons of the result was communicated to the study participants. In general, the study was conducted in accordance with the Declaration of Helsinki.

\section{Result}

\section{Background Characteristics}

A total of 107 patients using psychotropic medications and 107 apparently healthy controls were enrolled in the study. The mean age of patients was 30.95 ( $\mathrm{SD} \pm 9.6$ ) years, and for healthy controls was 30.59 ( $\mathrm{SD} \pm 8.96)$. Nearly three-fourth $80(74.8 \%)$ of the patients and controls were males. Almost half of the patient $54(50.5 \%)$ and $42(39.3 \%)$ of the controls live in urban settings. Of the total patients using psychotropic medications, 57 (53.3\%), 28 (26.2\%), and 21 (19.6\%) had schizophrenia, bipolar disorder, and depression respectively. About $75(70.1 \%)$ of the patients had duration of illness greater than 12 months. Regarding type of drugs, about 54 $(50.5 \%)$ of patients have been taking antipsychotics only, 14 (13.1\%) mood stabilizers only, 11 (10.3\%) antidepressants only, and 28 (26.1\%) took combination therapy of either of the above medications (Figure 1). A total of $72(67.3 \%)$ patients were used the drug for more than 12 months.

\section{Bacterial Profile and Antimicrobial Resistance Patterns of Isolates}

From 214 stool samples collected from both groups, 124 and 121 bacteria were isolated from patients and apparently healthy controls respectively. The most frequently isolated bacteria from patients and apparently healthy controls were E. coli, which was $100(80.6 \%)$ and 102 $(84.3 \%)$ respectively (Table 1$)$. Among 100 E. coli isolated from patients, $99(99.0 \%)$ were resistant to tetracycline and ampicillin each and $58(58.0 \%)$ to cefotaxime. On the other hand, among bacteria isolated from control groups, 96 (94.1\%), 57 (55.9\%) and $50(49.0 \%)$ of E. coli were found to be resistant to ampicillin, tetracycline, and trimethoprim-sulfamethoxazole, respectively. Generally, the proportion of resistant isolates of cases were higher than the isolates of controls in all of the tested antibiotics except trimethoprim-sulfamethoxazole (Table 1).

\section{Comparison of Drug Resistance Pattern of $E$. coli Isolated from Patients Taking Psychotropic Drugs with Apparently Healthy Controls}

Escherichia coli is the leading bacteria isolated from both group of participants. Comparison of antibiotic resistance 


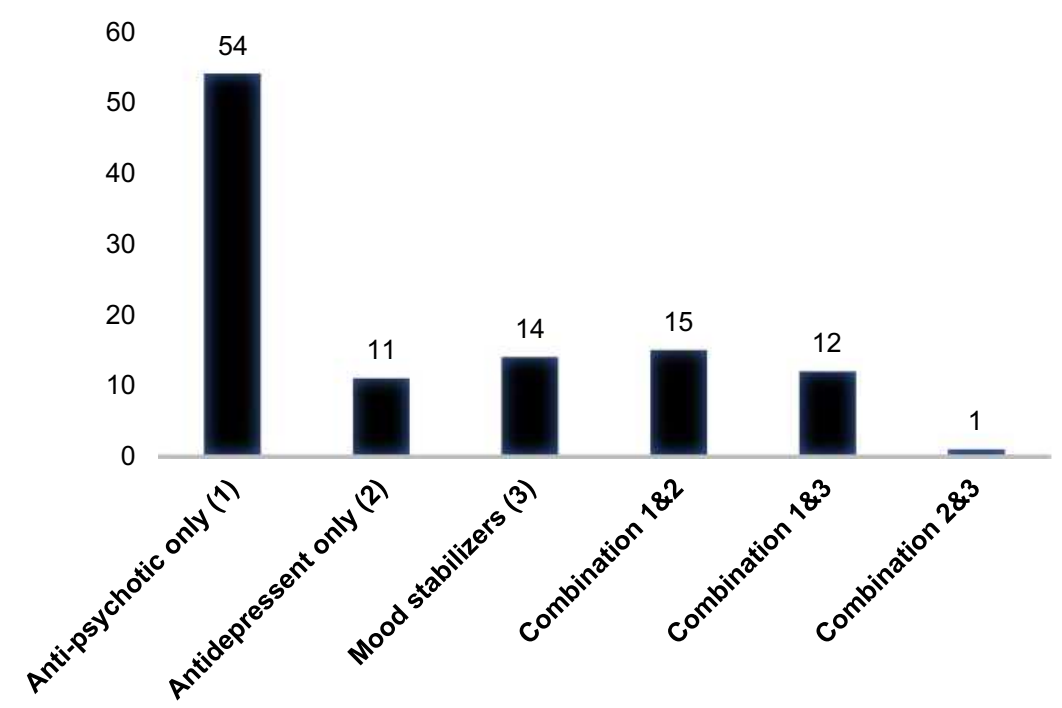

Figure I The proportion of psychotropic drugs used by cases at Jimma Medical Center. X-axis: Types of drugs. Y-axis: Number of cases.

pattern of E. coli was described in (Table 2). Accordingly, amoxicillin clavulanic acid, cefuroxime, ceftriaxone, cefepime, cefotaxime, meropenem, ciprofloxacin, and tetracycline resistance are significantly higher among $E$. coli bacteria isolated from participants taking psychotropic drugs than E. coli bacteria isolated from apparently healthy controls (Table 2).

\section{Multidrug Resistance in Bacterial Isolates}

The overall rate of multidrug resistance (resistant to at least one agent in three or more antimicrobial categories) among bacteria isolated from psychiatry patients were 78 (63\%) whereas it accounts 51 (42.1\%) among bacteria isolated from apparently healthy controls. The odds of isolating MDR bacteria from patients was higher than healthy controls $[\mathrm{OR}=5.4,95 \%$ C. I: (1.5-29.8)] (Table 3). The majority of MDR bacteria 48 (61.5\%) and $29(56.9 \%)$ were isolated from the age category between 25 and 34 years from patients and healthy controls respectively. More than half $42(53.8 \%)$ of MDR bacteria were isolated from patients who had

Table I Drug Resistance Patterns of Bacteria Isolated from Cases and Controls to Different Antibiotics

\begin{tabular}{|c|c|c|c|c|c|c|c|c|c|c|c|c|c|c|c|}
\hline \multicolumn{2}{|l|}{ Isolated Bacteria } & \multirow{3}{*}{$\begin{array}{c}\text { AMP } \\
99 \\
96\end{array}$} & \multirow{3}{*}{$\begin{array}{c}\mathbf{C N} \\
1 \\
0\end{array}$} & \multirow{3}{*}{$\begin{array}{c}\text { AMC } \\
17 \\
5\end{array}$} & \multirow{3}{*}{$\begin{array}{c}\text { CXM } \\
19 \\
8\end{array}$} & \multirow{3}{*}{$\begin{array}{c}\text { CRO } \\
18 \\
6\end{array}$} & \multirow{3}{*}{$\begin{array}{c}\text { CAZ } \\
18 \\
10\end{array}$} & \multirow{3}{*}{$\begin{array}{c}\text { FEP } \\
26 \\
6\end{array}$} & \multirow{3}{*}{$\begin{array}{c}\text { CTX } \\
58 \\
17\end{array}$} & \multirow{3}{*}{$\begin{array}{c}\text { MRP } \\
21 \\
5\end{array}$} & \multirow{3}{*}{$\begin{array}{c}\text { CIP } \\
17 \\
5\end{array}$} & \multirow{3}{*}{$\begin{array}{c}\text { SXT } \\
\begin{array}{l}36 \\
50\end{array}\end{array}$} & \multirow{3}{*}{$\begin{array}{c}\text { CHL } \\
\begin{array}{c}8 \\
7\end{array}\end{array}$} & \multirow{3}{*}{$\begin{array}{c}\text { AMS } \\
23 \\
25\end{array}$} & \multirow{3}{*}{$\begin{array}{l}\text { TE } \\
99 \\
57\end{array}$} \\
\hline E. coli & Group A $(n=100)$ & & & & & & & & & & & & & & \\
\hline & Group B $(n=102)$ & & & & & & & & & & & & & & \\
\hline \multirow[t]{2}{*}{ Klebsiella spp. } & Group A $(n=8)$ & 8 & 0 & 0 & 0 & 0 & I & I & 6 & 2 & 1 & 4 & 0 & 1 & 8 \\
\hline & Group B $(n=9)$ & 9 & 0 & 0 & 0 & 0 & 0 & 0 & 0 & 0 & 2 & 6 & 1 & 1 & 7 \\
\hline \multirow[t]{2}{*}{ Enterobacter spp. } & Group A $(n=6)$ & 6 & 0 & 0 & 1 & I & 1 & 1 & 2 & 0 & 1 & I & I & 0 & 6 \\
\hline & Group B $(n=6)$ & 6 & 0 & 0 & 0 & I & 0 & 0 & 2 & 0 & 0 & 0 & 0 & 0 & 5 \\
\hline \multirow[t]{2}{*}{ Citrobacter spp. } & Group A $(n=6)$ & 6 & 0 & I & 2 & 2 & 2 & 3 & 4 & 0 & 2 & 2 & 2 & 4 & 6 \\
\hline & Group B $(n=3)$ & 3 & 0 & 0 & 0 & 0 & 0 & 0 & 0 & 0 & 0 & 2 & I & 1 & 1 \\
\hline \multirow[t]{2}{*}{ S. rubidaea } & Group A $(n=1)$ & I & 0 & 0 & 0 & 0 & 1 & 0 & 0 & 0 & 0 & I & 0 & 1 & $\mathrm{I}$ \\
\hline & Group B $(n=1)$ & I & 0 & 0 & 0 & 0 & 0 & 0 & 0 & 0 & 0 & I & 0 & 1 & I \\
\hline P. agglomerans $(n=3)$ & Group A $(n=3)$ & 3 & 0 & I & 0 & 0 & 0 & 0 & 3 & 0 & 0 & I & 0 & 2 & 3 \\
\hline \multirow[t]{2}{*}{ Total $(n=245)$} & Group A $(n=124)$ & 123 & I & 19 & 30 & 21 & 23 & 31 & 73 & 23 & 21 & 45 & I I & 31 & 123 \\
\hline & Group B $(n=|2|)$ & 115 & 0 & 5 & 8 & 7 & 10 & 6 & 19 & 5 & 7 & 59 & 9 & 8 & 71 \\
\hline
\end{tabular}

Notes: Group A, Psychiatry patients; Group B, Apparently health controls.

Abbreviations: AMP, Ampicillin; CN, Gentamycin; AMC, Amoxicillin-clavulanic Acid; CXM, Cefuroxime; CRO, Ceftriaxone; CAZ, Ceftazidime; FEP, Cefepime; CTX, Cefotaxime; MRP, Meropenem, CIP, Ciprofloxacin; SXT, Trimethoprim-sulfamethoxazole; CHL, Chloramphenicol; AMS, Ampicillin-sulbactam; TE, Tetracycline. 
Table 2 Comparison of Resistance Pattern Frequency of $E$. coli Isolated from Patients and Controls

\begin{tabular}{|c|c|c|c|c|c|}
\hline Antibiotic & Pattern & $\begin{array}{c}\text { E. coli } \\
\text { (Patients) }\end{array}$ & $\begin{array}{c}\text { E. coli } \\
\text { (Controls) }\end{array}$ & Chi-Square & P-value \\
\hline AMC & $\begin{array}{l}S \\
R\end{array}$ & $\begin{array}{l}83 \\
17\end{array}$ & $\begin{array}{c}97 \\
5\end{array}$ & 7.62 & 0.005 \\
\hline CXM & $\begin{array}{l}S \\
R\end{array}$ & $\begin{array}{l}81 \\
19\end{array}$ & $\begin{array}{c}94 \\
8\end{array}$ & 5.43 & 0.020 \\
\hline CRO & $\begin{array}{l}S \\
R\end{array}$ & $\begin{array}{l}82 \\
18\end{array}$ & $\begin{array}{c}96 \\
6\end{array}$ & 7.08 & 0.008 \\
\hline FEP & $\begin{array}{l}S \\
R\end{array}$ & $\begin{array}{l}74 \\
26\end{array}$ & $\begin{array}{c}96 \\
6\end{array}$ & 15.33 & 0.000 \\
\hline CTX & $\begin{array}{l}S \\
R\end{array}$ & $\begin{array}{l}42 \\
58\end{array}$ & $\begin{array}{l}85 \\
17\end{array}$ & 36.96 & 0.000 \\
\hline MRP & $\begin{array}{l}\mathrm{S} \\
\mathrm{R}\end{array}$ & $\begin{array}{l}79 \\
21\end{array}$ & $\begin{array}{c}97 \\
5\end{array}$ & 11.67 & 0.001 \\
\hline CIP & $\begin{array}{l}\mathrm{S} \\
\mathrm{R}\end{array}$ & $\begin{array}{l}83 \\
17\end{array}$ & $\begin{array}{c}97 \\
5\end{array}$ & 7.62 & 0.005 \\
\hline TE & $\begin{array}{l}S \\
R\end{array}$ & $\begin{array}{c}1 \\
99\end{array}$ & $\begin{array}{l}45 \\
57\end{array}$ & 53.38 & 0.000 \\
\hline Total & & 100 & 102 & & \\
\hline
\end{tabular}

Abbreviations: AMC, Amoxicillin-clavulanic Acid; CXM, Cefuroxime; CRO, Ceftriaxone; FEP, Cefepime; CTX, Cefotaxime; MRP, Meropenem; CIP, Ciprofloxacin; TE, Tetracycline; S, Susceptible; R, Resistance.

Table 3 The Association Between Psychotropic Drug Use with ESBL-Producing and MDR Bacteria of Gut

\begin{tabular}{|l|c|c|c|c|c|c|}
\hline \multirow{2}{*}{ Variables } & \multicolumn{2}{|c|}{ ESBL Producer } & \multirow{2}{*}{ Odds Ratio } & \multicolumn{2}{|c|}{ MDR } \\
\cline { 2 - 3 } & Yes & No & & Yes & No \\
\hline Cases & 15 & 109 & $5.4(1.5-29.8)$ & 78 & 46 & $2.3(1.4-4.0)$ \\
Controls & 3 & 118 & $P \leq 0.003$ & 51 & 70 & $P \leq 0.001$ \\
\hline
\end{tabular}

Abbreviations: MDR, resistant to at least one agent in three or more antimicrobial categories; ESBL, extended spectrum beta-lactamases.

Schizophrenia, 56 (71.8\%) were from patients with duration of illness for more than one year, 41 (52.6\%) were from patients who have been taking antipsychotic medications only and $52(66.7 \%)$ were from patients who had used the drug for more than one year.

\section{Proportion of ESBL-Producing Isolates}

Out of the total 124 bacteria isolated from patients, 15 (12.1\%) were ESBL producers. Likewise, out of the 100 E. coli bacteria isolated from patients, 13 (13\%) were ESBL producers. In comparison, only three E. coli bacteria isolated from the healthy controls were ESBL producers. More than half of ESBL-producing bacteria $8(53.3 \%)$ were isolated from patients with schizophrenia, having duration of illness greater than 1 year, and treated with antipsychotic drugs only. In this study, the proportion of ESBL-producing bacterial isolates were higher in cases than controls $(12.1 \%$ vs $2.5 \%)$. The odds of isolating ESBL-producing Enterobacteriaceae is higher on patients than healthy controls $(\mathrm{OR}=2.3,95 \%$ C.I: (1.4-4.0)) (Table 3).

\section{Discussion}

A total of 245 bacteria were isolated from the participants. There is no difference in bacteria profile isolated from patients and healthy controls. The most frequently isolated bacteria from patients and healthy controls were E. coli, followed by Klebsiella and Enterobacter species. This might be due to the close similarity in the age, geographical region, and environment for both groups, which are the possible factors that affect the composition of gut 
bacteria. ${ }^{16}$ The predominance of E. coli and Klebsiella species in this finding was supported by a research done in Nepalese. ${ }^{17}$

In this study, it is observed that amoxicillin clavulanic acid, cefuroxime, ceftriaxone, cefepime, cefotaxime, meropenem, ciprofloxacin, and tetracycline resistance are more common among E. coli isolated from participants taking psychotropic drugs. Conversely there is no statistical difference against ampicillin, gentamicin, ceftazidime, trimethoprimsulfamethoxazole, chloramphenicol and ampicillinsulbactam. Depicting the mechanism for the observed high resistance of $E$. coli isolated from patients using psychotropic medications is out of the scope of this study. However, one previous evidence has indicated that $E$. coli exposed to fluoxetine increased resistance to tetracycline via the overproduction of reactive oxygen species, which causes mutations in the transcriptional regulator genes that result in the overexpression of the multidrug efflux system and promote antibiotics efflux and decreased outer membrane porin protein to block antibiotics from entering the cell. ${ }^{11}$ Furthermore, another study in the Slovak showed high proportion of antibiotic resistance in coliforms isolated from wastewater with high concentration of psychoactive compounds like cotinine, tramadol, methamphetamine and venlafaxine, and compounds. ${ }^{18}$

Multidrug resistant (MDR) and extended spectrum beta lactam antibiotic resistance was higher on bacteria isolated from patients using psychotropic drug as compared with isolates from apparently health controls. This inferred that psychotropic drug use might have a direct contribution for the emergence of MDR and ESBL-producing gut bacteria in psychotropic medication users. This hypothesis is substantiated by previous study which reported that MDR was observed in commensal bacteria isolated from patients who took psychotropic drug due to the induction of multiple antibiotics resistance genes. $^{11}$

Although there is no much evidence about the contribution of psychotropic drugs in the emergence of antibiotic resistance in gut bacteria, the studies done in different parts of the world depicted exposure to the antidepressants like fluoxetine, ${ }^{11,19}$ a tricyclic antidepressant (amitriptyline hydrochloride), ${ }^{20}$ escitalopram $^{19}$ sertraline and paroxetine ${ }^{21,22}$ have been shown to have antimicrobial activity against Gram-positive and Gram-negative bacteria residing in the human gut such as E. coli, L. rhamnosus, Citrobacter and P. aeruginosa.

These psychotropic drugs could contribute to drug resistance in different ways. The use of antipsychotic drugs may also cause the bacteria to induce both ESBL and AmpC production which might be due to mutation of genes that encode beta-lactamases enzyme, modifications of the antimicrobial target, activation of efflux mechanisms to extrude the drug and global changes in important metabolic pathways via modulation of regulatory networks. ${ }^{23}$

Generally, prolonged antimicrobial effects of psychotropic drugs may cause the emergence of drug resistance in commensal gut bacteria, gut colonization with MDR commensal bacteria could be the source of infections to themselves, their families, other individuals, hospitalized patients, and the community at large. ${ }^{7}$

\section{Conclusion}

There is a high antibiotic resistance Enterobacteriaceae among patients using psychotropic medications than health controls. Specifically, E. coli isolated from patients using psychotropic medications showed significantly higher resistance against tested beta lactam and other antibiotics. The magnitude of ESBL-producing and MDR bacteria carriage among patients using psychiatric medications were very concerning.

\section{Abbreviations}

ESBL, Extended spectrum betalactamase; JMC, Jimma Medical Center; MDR, Multidrug resistant.

\section{Data Sharing Statement}

The data used in the findings of this study are included in the manuscript.

\section{Ethics Approval and Consent to Participate}

The study was approved by the Institutional Review Board of Institute of Health, Jimma University.

\section{Consent for Publication}

Not applicable - This manuscript does not contain any individual person's data.

\section{Acknowledgment}

We are gratefully to thank Jimma University for funding this work and data collectors and study participants are highly acknowledged.

\section{Author Contributions}

All authors made a significant contribution to the work reported, whether that is in the conception, study design, execution, acquisition of data, analysis and interpretation, or in all these areas; took part in drafting, revising or 
critically reviewing the article; gave final approval of the version to be published; have agreed on the journal to which the article has been submitted; and agree to be accountable for all aspects of the work.

\section{Funding}

This project was funded by Jimma University through the Institute of Health, Research and Postgraduate Office.

\section{Disclosure}

All the authors declare that they have no competing interests.

\section{References}

1. Wellington EM, Boxall AB, Cross $\mathrm{P}$, et al. The role of the natural environment in the emergence of antibiotic resistance in Gram-negative bacteria. Lancet Infect Dis. 2013;13(2):155-165. doi:10.1016/S1473-3099(12)70317-1

2. Leonard AF, Zhang L, Balfour AJ, et al. Exposure to and colonization by antibiotic-resistant E. coli in UK coastal water users: environmental surveillance, exposure assessment, and epidemiological study (Beach Bum Survey). Environ Int. 2018;114:326-333. doi:10.1016/j. envint.2017.11.003

3. Han R, Shi Q, Wu S, et al. Dissemination of Carbapenemases (KPC, NDM, OXA-48, IMP, and VIM) among Carbapenem-Resistant Enterobacteriaceae isolated from adult and children patients in China. Front Cell Infect Microbiol. 2020;10:314. doi:10.3389/ fcimb.2020.00314

4. Yu X, Zhang M, Zuo J, et al. Evaluation of antibiotic resistant lactose fermentative opportunistic pathogenic Enterobacteriaceae bacteria and blaTEM-2 gene in cephalosporin wastewater and its discharge receiving river. $J$ Environ Manage. 2018;228:458-465. doi:10.1016/j. jenvman.2018.09.043

5. Iseppi R, Di Cerbo A, Messi P, Sabia C. Antibiotic Resistance and Virulence Traits in Vancomycin-Resistant Enterococci (VRE) and Extended-Spectrum-Lactamase/AmpC-producing (ESBL/AmpC) Enterobacteriaceae from Humans and Pets. Antibiotics. 2020;9 (4):152. doi:10.3390/antibiotics9040152

6. Van Schaik W. The human gut resistome. Philos Trans R Soc B Biol Sci. 2015;370(1670):20140087. doi:10.1098/rstb.2014.0087

7. Carlet J. The gut is the epicenter of antibiotic resistance. Antimicrob Resist Infect Control. 2012;1(1):39. doi:10.1186/2047-2994-1-39

8. Hasan N, Yang H. Factors affecting the composition of the gut microbiota, and its modulation. PeerJ. 2019;7:e7502. doi:10.7717/ peerj. 7502

9. Maier L, Pruteanu M, Kuhn M, et al. Extensive impact of non-antibiotic drugs on human gut bacteria. Nature. 2018;555 (7698):623-628. doi:10.1038/nature25979

Infection and Drug Resistance

\section{Publish your work in this journal}

Infection and Drug Resistance is an international, peer-reviewed openaccess journal that focuses on the optimal treatment of infection (bacterial, fungal and viral) and the development and institution of preventive strategies to minimize the development and spread of resistance. The journal is specifically concerned with the epidemiology of
10. Cederlund H, Mårdh P-A. Antibacterial activities of non-antibiotic drugs. J Antimicrob Chemother. 1993;32(3):355-365. doi:10.1093/ $\mathrm{jac} / 32.3 .355$

11. Jin M, Lu J, Chen Z, et al. Antidepressant fluoxetine induces multiple antibiotics resistance in Escherichia coli via ROS-mediated mutagenesis. Environ Int. 2018;120:421-430. doi:10.1016/j. envint.2018.07.046

12. Oluyege A, Ojo-Bola O, Oludada O. Carriage of antibiotic resistant commensal E. coli in infants below 5 months in Ado-Ekiti. Int J Curr Microbiol Appl Sci. 2015;4:1096-1102.

13. Ayalew M, Workicho A, Tesfaye E, Hailesilasie H, Abera M. Burden among caregivers of people with mental illness at Jimma University Medical Center, Southwest Ethiopia: a cross-sectional study. Ann Gen Psychiatry. 2019;18(1):10. doi:10.1186/s12991-019-0233-7

14. Cheesbrough M. District Laboratory Practice in Tropical Countries, Part 2. Cambridge University Press; 2006.

15. Clinical and Laboratory Standards Institute. Performance Standards for Antimicrobial Susceptibility Testing. Wayne, PA: Clinical and Laboratory Standards Institute; 2017.

16. Mueller S, Saunier K, Hanisch C, et al. Differences in fecal microbiota in different European study populations in relation to age, gender, and country: a cross-sectional study. Appl Environ Microbiol. 2006;72(2):1027-1033. doi:10.1128/AEM.72.2.10271033.2006

17. Maharjan A, Bhetwal A, Shakya S, et al. Ugly bugs in healthy guts! Carriage of multidrug-resistant and ESBL-producing commensal Enterobacteriaceae in the intestine of healthy Nepalese adults. Infect Drug Resist. 2018;11:547. doi:10.2147/IDR.S156593

18. Mackul'ak T, Medvecká E, Staňová AV, et al. Boron doped diamond electrode-The elimination of psychoactive drugs and resistant bacteria from wastewater. Vacuum. 2020;171:108957. doi:10.1016/j. vacuum.2019.108957

19. Cussotto S, Strain CR, Fouhy F, et al. Differential effects of psychotropic drugs on microbiome composition and gastrointestinal function. Psychopharmacology. 2019;236(5):1671-1685. doi:10.1007/s00213-018-5006-5

20. Mandal A, Sinha C, Jena AK, Ghosh S, Samanta A. An investigation on in vitro and in vivo antimicrobial properties of the antidepressant: amitriptyline hydrochloride. Braz J Microbiol. 2010;41(3):635-642. doi:10.1590/S1517-83822010000300014

21. Bohnert JA, Szymaniak-Vits M, Schuster S, Kern WV. Efflux inhibition by selective serotonin reuptake inhibitors in Escherichia coli. J Antimicrob Chemother. 2011;66(9):2057-2060. doi:10.1093/jac/ dkr258

22. Munoz-Bellido J, Munoz-Criado S, Garcia-Rodriguez J. Antimicrobial activity of psychotropic drugs: selective serotonin reuptake inhibitors. Int J Antimicrob Agents. 2000;14(3):177-180. doi:10.1016/S0924-8579(99)00154-5

23. Munita JM, Arias CA. Mechanisms of antibiotic resistance. In: Virulence Mechanisms of Bacterial Pathogens. 2016:481-511. antibiotic resistance and the mechanisms of resistance development and diffusion in both hospitals and the community. The manuscript management system is completely online and includes a very quick and fair peerreview system, which is all easy to use. Visit http://www.dovepress.com/ testimonials.php to read real quotes from published authors. 